\title{
Distribution of GFRA1-expressing spermatogonia in adult mouse testis
}

\author{
Margherita Grasso, Andrea Fuso ${ }^{1}$, Lisa Dovere, Dirk G de Rooij ${ }^{2,3}$, Mario Stefanini, Carla Boitani \\ and Elena Vicini \\ Fondazione Pasteur Cenci Bolognetti, Section of Histology and Medical Embryology, Department of Anatomical, \\ Histological, Forensic and Orthopaedic Sciences, 'La Sapienza' University of Rome, Via Antonio Scarpa 14, 00161 \\ Rome, Italy, ${ }^{1}$ Department of Surgery, 'La Sapienza' University of Rome, Rome, Italy, ${ }^{2}$ Department of Endocrinology, \\ Faculty of Science, Utrecht University, Utrecht, The Netherlands and ${ }^{3}$ Center for Reproductive Medicine, Academic \\ Medical Center, University of Amsterdam, Amsterdam, The Netherlands
}

Correspondence should be addressed to E Vicini; Email: elena.vicini@uniroma1.it

\begin{abstract}
In mice and other mammals, spermatogenesis is maintained by spermatogonial stem cells (SSCs), a cell population belonging to undifferentiated type A spermatogonia. In the accepted model of SSC self-renewal, Asingle (As) spermatogonia are the stem cells, whereas paired (Apaired (Apr)) and chained (Aaligned (Aal)) undifferentiated spermatogonia are committed to differentiation. This model has been recently challenged by evidence that As and chained (Apr and Aal), undifferentiated spermatogonia are heterogeneous in terms of gene expression and function. The expression profile of several markers, such as GFRA1 (the GDNF co-receptor), is heterogeneous among As, Apr and Aal spermatogonia. In this study, we have analysed and quantified the distribution of GFRA1-expressing cells within the different stages of the seminiferous epithelial cycle. We show that in all stages, GFRA1 + chained spermatogonia (Apr to Aal) are more numerous than GFRA1 + As spermatogonia. Numbers of chained GFRA1 + spermatogonia are sharply reduced in stages VII-VIII when Aal differentiate into A1 spermatogonia. GFRA1 expression is regulated by GDNF and in cultures of isolated seminiferous tubules, we found that GDNF expression and secretion by Sertoli cells is stage-dependent, being maximal in stages II-VI and decreasing thereafter. Using qRT-PCR analysis, we found that GDNF regulates the expression of genes such as Tex14, Sohlh1 and Kit (c-Kit) known to be involved in spermatogonial differentiation. Expression of Kit was upregulated by GDNF in a stage-specific manner. Our data indicate that GDNF, besides its crucial role in the self-renewal of stem cells also functions in the differentiation of chained undifferentiated spermatogonia. Reproduction (2012) 143 325-332
\end{abstract}

\section{Introduction}

In mice and other mammals, spermatogenesis is maintained by spermatogonial stem cells (SSCs), a subpopulation of the undifferentiated type A spermatogonia. These undifferentiated spermatogonia can be found as single cells (Asingle (As)) or as chains of two (Apaired (Apr)) or up to 16-32 cells (Aaligned (Aal)) connected by intercellular bridges. According to the 'As model', As spermatogonia are the stem cells of spermatogenesis, whereas longer clones of cells are committed to differentiation (Huckins 1971b, Oakberg 1971, Lok et al. 1982). The As either self-renew by forming single cells or generate pairs of cells (Apr), which are connected by an intercellular bridge as a result of incomplete cytokinesis. Therefore, As always undergo symmetric cell division, and during the steady state, the ratio between self-renewal and differentiation is close to 1 (de Rooij 2001).

Spermatogenesis is a cyclic process that in the mouse is divided into 12 stages, each representing a unique association of germ cells at different steps of differentiation. The relationship between spermatogenic stages and the kinetics of undifferentiated spermatogonia proliferation has been analysed in different mammalian species (Phillips et al. 2010). In the mouse, morphometric analysis performed on whole mounts of seminiferous tubules indicates that As and Apr numbers remain relatively constant throughout the stages of spermatogenesis while the density of Aals fluctuates cyclically (Tegelenbosch \& de Rooij 1993). All classes of undifferentiated spermatogonia randomly divide primarily in stages $\mathrm{X}-\mathrm{II}$, and subsequently, during stages VII and VIII, almost all of the larger chains (Aal4-Aal32) differentiate into A1 spermatogonia (Schrans-Stassen et al. 1999). This event marks the transition from the randomly cycling population of undifferentiated spermatogonia to the rigidly controlled series of mitotic divisions of differentiating spermatogonia, which are highly synchronised. All subsequent divisions of A1, A2, A3, A4, In, B spermatogonia and primary spermatocytes 
occur in a stage-specific fashion (de Rooij 2001). The transition between undifferentiated and differentiating spermatogonia is a finely regulated step that is marked by a reduction in cell cycle length (Huckins 1971a, 1971b, Lok \& de Rooij 1983, Lok et al. 1983) and a gene expression profile switch (Schrans-Stassen et al. 1999, Beumer et al. 2000). Undifferentiated spermatogonia express the transcriptional repressor ZBTB16 (PLZF) while its expression is downregulated thereafter (Buaas et al. 2004, Costoya et al. 2004). Initiation of the expression of KIT (c-KIT) marks the transition from Aal to A1 spermatogonia (Schrans-Stassen et al. 1999).

The 'As model' has recently been challenged by evidence, from our and other laboratories, which indicates that As and chained undifferentiated spermatogonia are heterogeneous in terms of gene expression and function. The expression profile of $\mathrm{CDH} 1, \mathrm{LIN} 28$, GFRA1, NANOS2, NANOS3 and NEUROG3 (NGN3) is heterogeneous among As, Apr and Aal spermatogonia (Grisanti et al. 2009, Suzuki et al. 2009, Zheng et al. 2009, Nakagawa et al. 2010); moreover, different subsets of As cells may be generated through an asymmetric division (Grisanti et al. 2009, Suzuki et al. 2009). Data from transgenic animal models were interpreted to mean that two functionally distinct stem cell compartments exist: the actual and the potential stem cell compartments, which may play different roles in different conditions. Furthermore, in vivo time-lapse observations suggest that occasionally longer clones of Aal spermatogonia undergo fragmentation, opening the possibility that pinched cells become new As or Apr cells (Nakagawa et al. 2010). Altogether, these studies encourage further studies into the validity of the 'As model'. Furthermore, elucidation of the lineage relationship within undifferentiated spermatogonia compartments deserves further investigation.

To gain more insight into the lineage relationship of different subsets of undifferentiated spermatogonia, we have analysed and quantified the distribution of GFRA1-expressing cells within the subsequent stages of the seminiferous epithelial cycle. GFRA1 is the co-receptor for gdnf, a Sertoli cell-derived factor that controls the balance between self-renewal and differentiation of SSCs (Meng et al. 2000). The distribution of GFRA1-expressing cells, along with the gene expression profiles of candidate genes after GDNF in vitro treatment of intact expressing seminiferous tubules, suggests that, apart from regulating stem cell self-renewal, surprisingly GDNF also stimulates cells to progress along the differentiation pathway.

\section{Results} Distribution of GFRA1 + A spermatogonia during the
seminiferous epithelial cycle

To analyse the expression pattern of GFRA1 within undifferentiated spermatogonia, intact seminiferous tubules were co-stained for GFRA1 and ZBTB16, a marker of all types of undifferentiated spermatogonia (Buaas et al. 2004, Costoya et al. 2004). Figure 1 shows the frequency of GFRA1 + and GFRA1 - clones for each class of undifferentiated spermatogonia obtained by morphometric analysis of mixed seminiferous tubules. In agreement with published data, our results show that the frequency of GFRA1 + spermatogonia decreases as spermatogonia progress from As to Aal (Nakagawa et al. 2010). In addition to single cells and chains of two, four, eight and 16 cells, a few groups of three ZBTB16+/ GFRA 1 + or GFRA 1 - cells were also observed. As no chains of six cells were observed during this study, we assumed that the groups of three were composed of a single and a pair, and they were counted as such. Possibly, these groups of three descended from false pairs, i.e. singles that did not yet migrate away from each other while one of the cells had already divided into a pair.

Next, we identified and quantified the numbers of GFRA $1+$ and GFRA 1 - cells in three groups of stages of the seminiferous epithelial cycle: stages II-VI, VII-VIII and IX-XI. Figure $2(\mathrm{~A}-\mathrm{C})$ shows representative images of GFRA1 and ZBTB16-stained tubules for each group. The total number of ZBTB16+ cells was similar in stages II$\mathrm{VI}$ and VII-VIII but significantly decreased in stages IX-XI $(P<0.05)$. Likewise, total numbers of GFRA 1 - undifferentiated spermatogonia were also similar in stages II-VI and VII-VIII but significantly decreased in stages IX-XI $(P<0.05)$. Conversely, the total number of GFRA1+ cells was similar in stages II-VI and VII-VIII but significantly increased in stages IX-XI $(P<0.05$; Fig. 3A). To further investigate the distribution of each population of undifferentiated spermatogonia, we counted clones of As, Apr and Aal (4-8) expressing GFRA1, in each group of stages (Fig. 3B). Statistical analysis showed that the number of GFRA1 + As and Apr clones did not significantly differ among the groups of stages. However, GFRA $1+$ clones composed of 4 or 8 were relatively numerous in stages IX-XI, decreased in

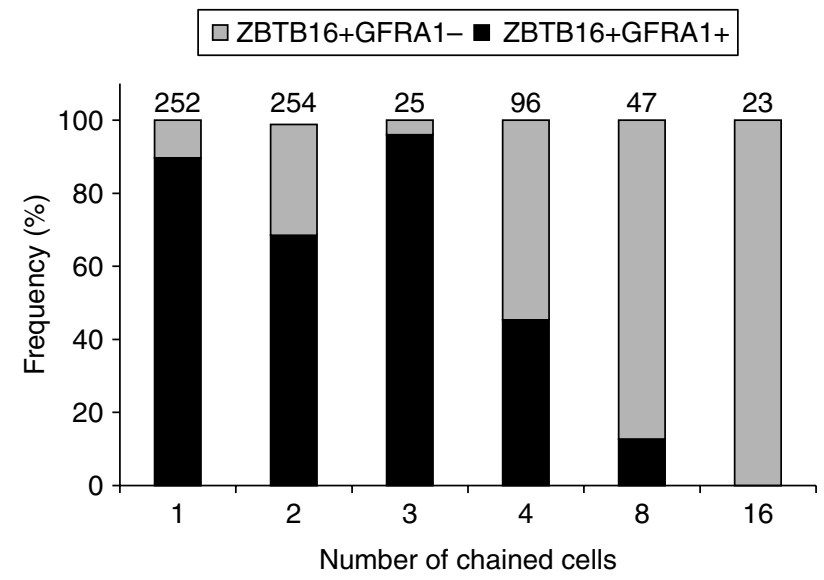

Figure 1 Frequency of spermatogonia clones positive or negative for GFRA1 expression. The number of clones examined in three different experiments is shown above each column. 

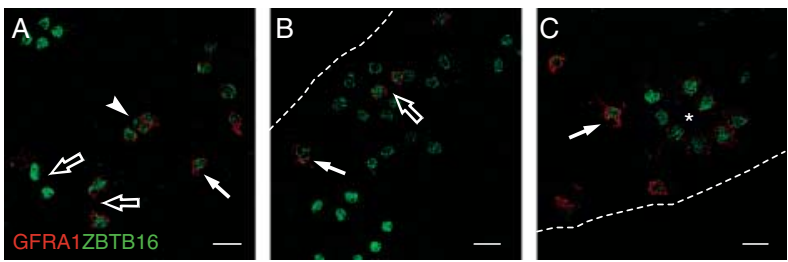

Figure 2 The distribution of GFRA1-expressing undifferentiated spermatogonia in the different stages of seminiferous epithelium. (A-C) Intact seminiferous tubules isolated from adult testis and staged were stained with anti-ZBTB16 (green), anti-GFRA1 (red) and TO-PRO-3 (blue). Pictures illustrate merged $Z$ sections. Representative pictures for each group of stages are shown: II-VI (A), VII-VIII (B) and IX-XI (C). Solid arrows, As spermatogonia; empty arrows, Apr spermatogonia; arrowheads, Aal4; asterisk, Aal8 spermatogonia. Bar, $20 \mu \mathrm{m}$.

stages II-VI and further reduced in stages VII-VIII $(P<0.05)$. Even though clones of ZBTB16+ Aal8 were found in all stages (Supplementary Figure 1, see section on supplementary data given at the end of this paper), clones of GFRA1 + Aal8 were only found in stages IX-XI. The large numbers of GFRA $1+$ chains of 4 and 8 cause the significant increase of GFRA $1+$ cells in stages IX-XI compared with the other stages (Fig. 3A). To further understand this point, for each group of stages, we calculated the numbers of As cells and the total number of cells in chains and expressed them as a percentage (single vs chained cells; Fig. 3C). Results show that in each group of stages, the number of positive cells in chains (Apr to Aal4-Aal8) outnumbered positive single cells (As), with a maximum in stages IX-XI $(81 \%$ of chained cells vs 19\% of As; Fig. 3C).

\section{GDNF expression and secretion during the cycle of the seminiferous epithelium}

GFRA1 is the specific co-receptor for GDNF. In the seminiferous epithelium GDNF is produced and secreted by Sertoli cells, a population of non-dividing somatic cells (Tadokoro et al. 2002). We addressed the question whether specific changes in gdnf expression occurred during the seminiferous epithelial cycle. Using real-time PCR we found that GDNF mRNA expression was higher in stages II-VI compared with stages VII-VIII $(P<0.05)$ and with stages IX-XI $(P<0.01)$ while there was no difference between stages VII-VIII and stages IX-XI (Fig. 4A).

To determine whether mRNA levels correlated to secreted protein levels, staged seminiferous tubules were maintained in culture for $24 \mathrm{~h}$ and GDNF released into the culture medium was measured by ELISA. As shown in Fig. 4B, secretion of GDNF was stage-dependent and paralleled mRNA levels, being maximal at stages II-VI.

\section{GDNF regulates genes expressed by spermatogonia}

Following the observations that i) GFRA1-expressing spermatogonia appear more frequently in chains than as single cells (As) and ii) GDNF levels are maximal at stages II-VI when undifferentiated spermatogonia are arrested in G0-G1 and are going to differentiate into A1 spermatogonia (Schrans-Stassen et al. 1999), we hypothesised that GDNF may control genes involved in spermatogonial differentiation. We analysed the expression level of known GDNF target genes, as well as genes involved in spermatogonial differentiation, by qRT-PCR after in vitro GDNF treatment of intact seminiferous tubules.

Microarray analysis, performed on SSC lines, showed that GDNF upregulates several genes, including Bcl6b and, intriguingly, its own receptor Gfra1; in contrast, GDNF downregulates Neurog3 (Oatley et al. 2006). We asked whether similar regulation by GDNF takes place
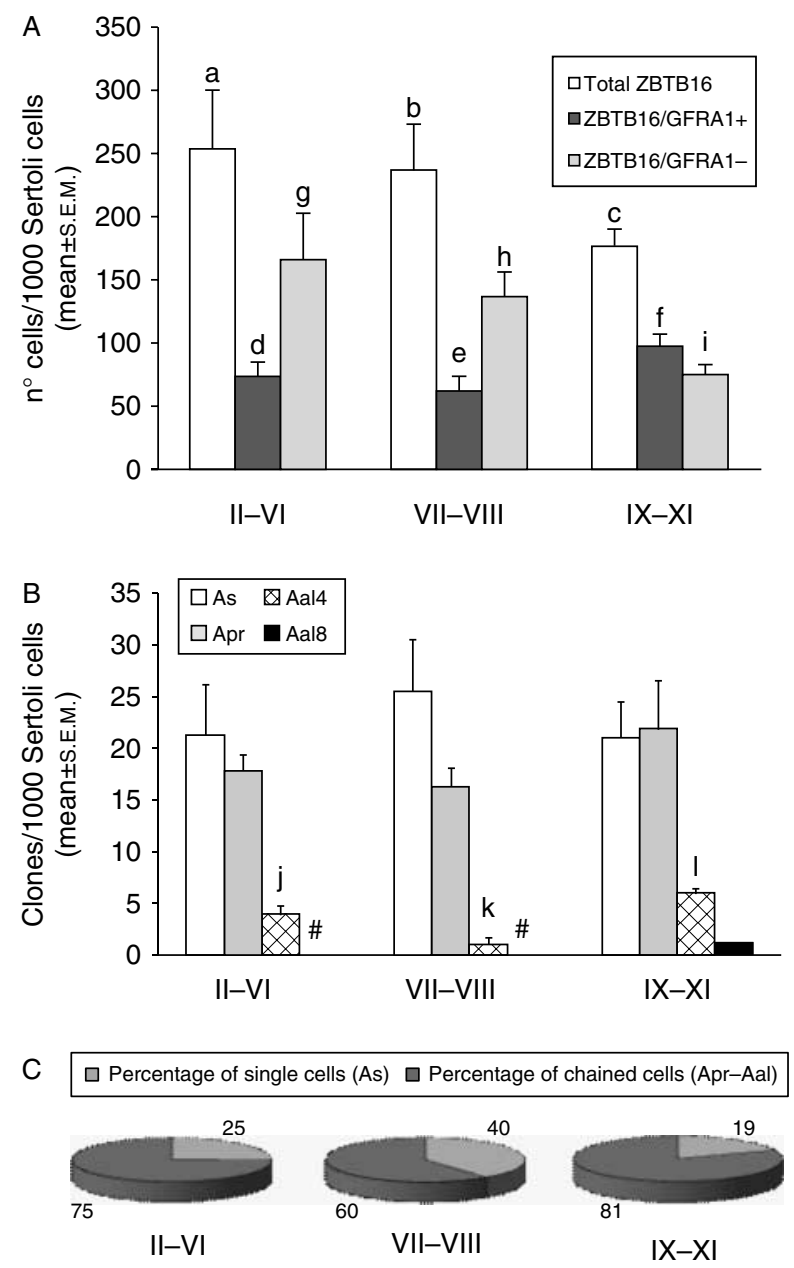

Figure 3 Morphometric analysis of GFRA1-labelled cell distribution in the different stages of the seminiferous epithelium. (A) Quantification of ZBTB16 +, GFRA1 + and GFRA1 - spermatogonia expressed as number of cells/1000 Sertoli cells. (B) Clone numbers of As, Apr, Aal4 and Aal8 for each group of stages. (C) Percentage of single cells (As) vs cells in chains (Apr-Aal) in each group of stages. Results are expressed as the mean \pm S.E.M.; $n=3$ experiments. c Significant difference vs a and b; f significant difference vs $d$ and e; i significant difference vs $g$ and $h$; I significant difference vs $\mathrm{j}$ and $\mathrm{k}(P<0.05)$. "Indicates that no Aal8 clones were present in stages II-VIII. Aal8 clones were present only in stages IX-XI. 

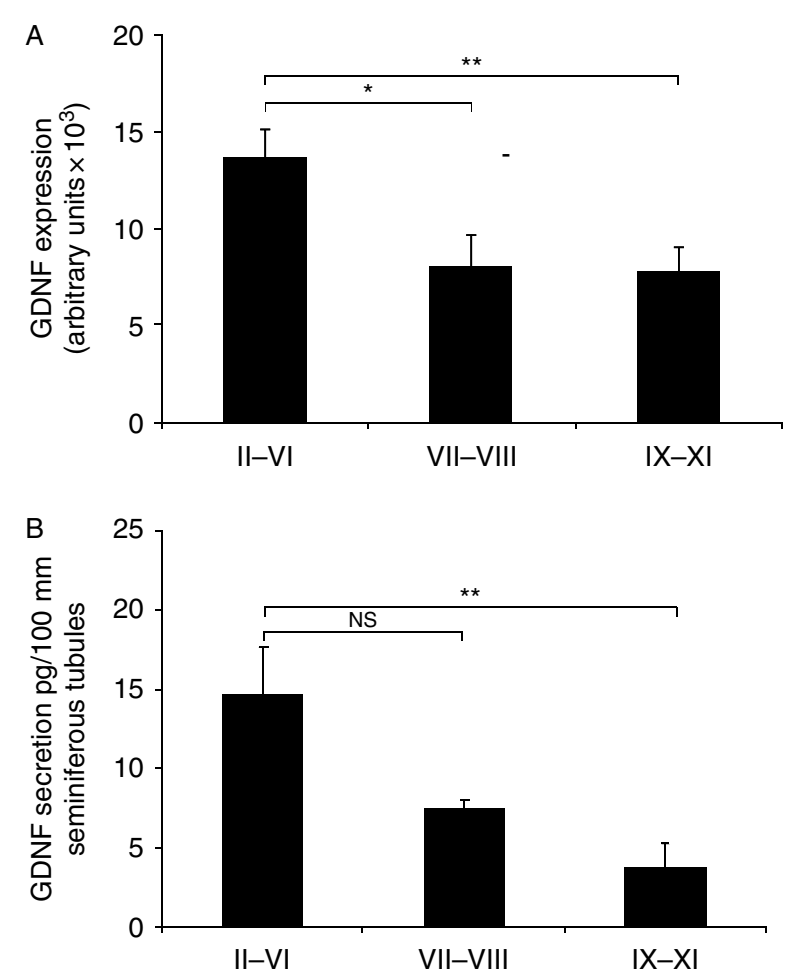

Figure $4 G d n f$ expression in different groups of stages. (A) Real-time PCR analysis of GDNF mRNA in staged, freshly isolated seminiferous tubules. Data are expressed as arbitrary units normalised to $\beta$-actin \pm S.E.M. Results are from $n=3$ experiments measured in duplicate. (B) ELISA quantification of GDNF released into medium by staged seminiferous tubules after $24 \mathrm{~h}$ of in vitro culture. Results are expressed as the mean \pm S.E.M.; $n=4$ experiments. ${ }^{*} P<0.05$ and ${ }^{* *} P<0.01$.

in intact seminiferous tubules. Mixed seminiferous tubules from adult mice were cultured in the absence or presence, of increasing GDNF concentrations (from 0 to $100 \mathrm{ng} / \mathrm{ml}$ ), and gene expression was assessed by qRT-PCR analysis (Fig. 5A). The results indicate that GDNF upregulates Gfra1 and Bcl6b mRNA levels and downregulates Neurog3 mRNA levels in a dosedependent manner (Fig. 5A).

Next, we investigated the impact of GDNF treatment on the expression level of genes involved in undifferentiated spermatogonia renewal/differentiation, specifically Tex14, Sohlh1, Kit and Pou5f1 (Oct4). Expression levels were measured in seminiferous tubules that were untreated or treated with $100 \mathrm{ng} / \mathrm{ml}$ GDNF. Bcl6b, Gfra1 and Neurog3 were included as internal controls (Fig. 5B). Interestingly, GDNF is able to upregulate Tex14, Sohlh1 and Kit mRNA levels and to downregulate Pou5f1 mRNA levels compared with controls (Fig. 4B). Because initiation of Kit expression marks the differentiation of Aal to A1 spermatogonia (SchransStassen et al. 1999), we analysed the impact of GDNF treatment on Kit expression levels in the different stages of the seminiferous epithelial cycle. In untreated seminiferous tubules, Kit mRNA is significantly higher in stages VII-VIII compared with other stages $(P<0.05)$. GDNF treatment affects Kit mRNA in a stage-dependent manner, Kit is upregulated in stages II-VIII $(P<0.05)$ but is unaffected in stages IX-XI (Fig. 5C). We next asked whether GDNF treatment altered the expression of target genes at the protein level. To this end, mixed seminiferous tubules from adult mice were cultured in the absence, or presence, of $100 \mathrm{ng} / \mathrm{ml}$ GDNF and protein extracts were analysed by Western blotting. Neither Kit nor Sohlh1 was found to be upregulated in GDNFtreated samples compared with controls (Supplementary Figure 2, see section on supplementary data given at the end of this article).

\section{Discussion}

In this study, we have shown that the number of undifferentiated spermatogonia, identified by the specific marker ZBTB16, changes during the cycle of the seminiferous epithelium, being lower in stages IX-XI, compared with other stages. In contrast, in stages IX-XI, the number of ZBTB16+/GFRA1+ cells was significantly higher than in other stages. The analysis of clone distribution revealed that while the numbers of clones of 1 and 2 GFRA $1+$ spermatogonia remain constant in all stages, clones of 4 and 8 GFRA $1+$ spermatogonia are differentially distributed with a significant decrease of GFRA1 + Aal4 in stages VII-VIII and relatively large numbers of GFRA1 + Aal4 and Aal8 clones in stages IX-XI. This further supports the concept of heterogeneity of gene expression among undifferentiated spermatogonia during the epithelial cycle (Grisanti et al. 2009, Nakagawa et al. 2010).

Interestingly, levels of GDNF mRNA and secreted protein also display a stage-specific profile, being maximal at stages $\mathrm{II}-\mathrm{VI}$ and reaching a minimum at stages IX-XI. These data are in line with a stagedependent expression of GDNF in the rat seminiferous tubules (Johnston et al. 2011). The finding that GDNF levels are high when the mitotic activity of undifferentiated spermatogonia is low (from stages II-III until stage X (de Rooij 2001)) suggests that GDNF might have a role in the differentiation of GFRA1 + Aal. In line with this, the numbers of clones of GFRA $1+\mathrm{Aal} 4$ were markedly reduced and GFRA1 + Aal8 were even absent in stages VII-VIII. Since under physiological conditions apoptosis takes place in differentiating spermatogonia but not in undifferentiated spermatogonia (de Rooij \& Janssen 1987, de Rooij \& Lok 1987) we interpret this as a consequence of the progression of GFRA1 + Aal clones into the next differentiation compartment. In addition, we found that Kit mRNA levels were significantly upregulated by GDNF during stages II-VIII. Since Kit expression marks the transition of undifferentiated to differentiating type A spermatogonia (Schrans-Stassen et al. 1999), our observation supports the idea that undifferentiated spermatogonial differentiation into A1 

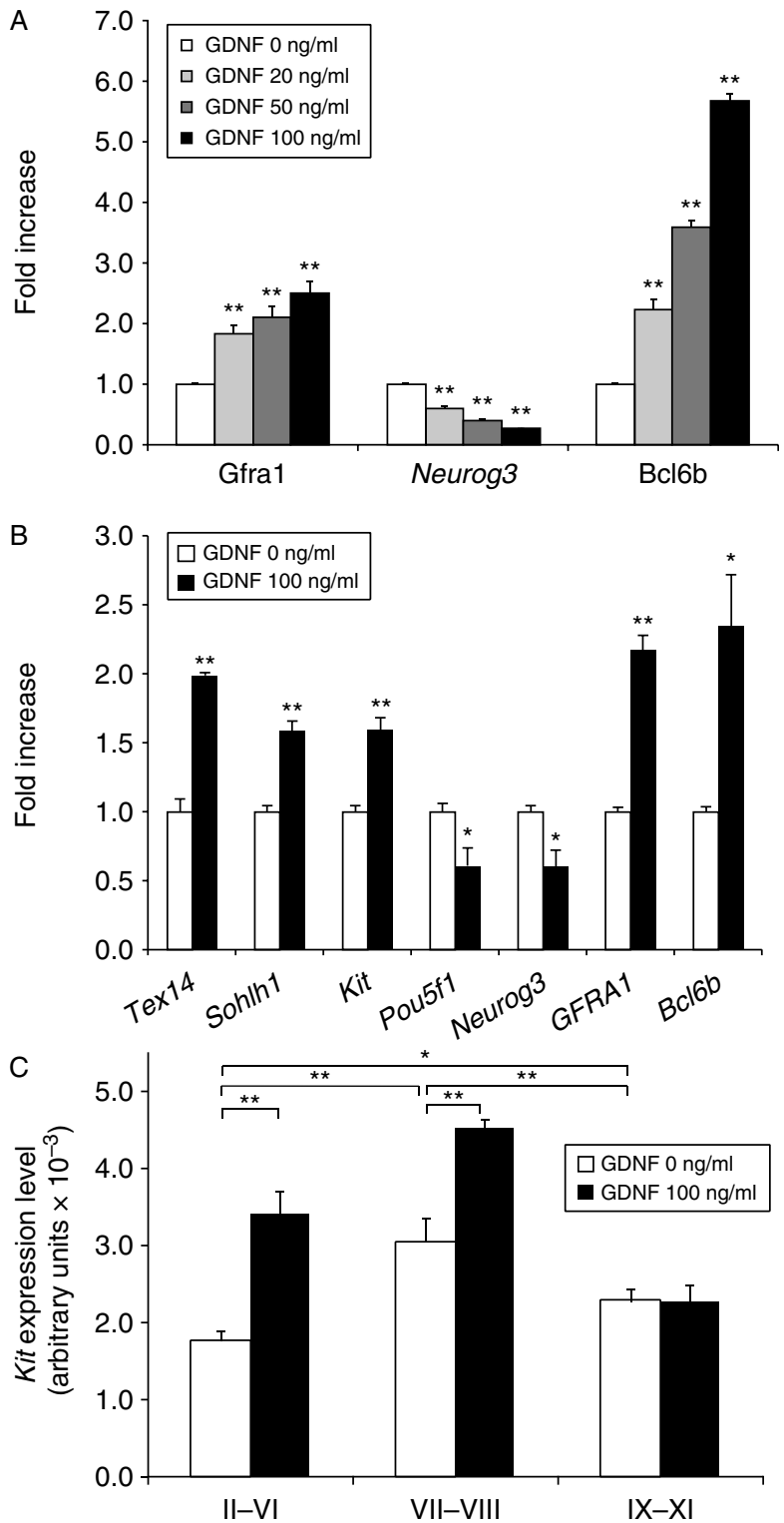

Figure 5 Regulation of spermatogonia-expressed genes by GDNF. (A) Real-time PCR analysis of Gfra1, Neurog3 and Bcl6b mRNAs in total seminiferous tubules treated with different concentrations of GDNF. $n=6,{ }^{* *} P<0.01$ vs control (GDNF, $0 \mathrm{ng} / \mathrm{ml}$; one-way ANOVA, Bonferroni post-hoc). (B) Real-time PCR analysis of Tex14, Sohlh1, Kit, Pou5f1, Neurog3, Gfra1 and Bcl6b mRNAs in seminiferous tubules treated, or untreated, with GDNF $100 \mathrm{ng} / \mathrm{ml} . n=3, * P<0.05$ and $* * P<0.01$ vs control (GDNF, $0 \mathrm{ng} / \mathrm{ml}$; $t$-test). (C) Real-time PCR analysis of Kit mRNA in different stages of seminiferous tubules treated, or untreated, with GDNF, $100 \mathrm{ng} / \mathrm{ml} n=3, * P<0.05$ and ${ }^{* *} P<0.01$. In $A$ and $B$, data are expressed as 'fold increase' with control indicated as $1 \pm$ S.E.M.; in $C$ data are expressed as arbitrary units normalised to $\beta$-actin \pm s.E.M.

spermatogonia might be facilitated by GDNF. An additional factor, involved in translational regulation, will be necessary to induce the actual synthesis of the KIT protein.

A list of GDNF-regulated genes has been generated through microarray analysis performed on freshly isolated mouse pup GFRA1-expressing type A spermatogonia or mouse SSC lines (Hofmann et al. 2005, Oatley et al. 2006). For instance, GDNF mediates the upregulation of several transcription factor-encoding genes $(\mathrm{N}-\mathrm{Myc}$, Egr2, Egr3, Bcl6b, Lhx1, etc.) and intriguingly Gfra1. In contrast, several genes were found to be downregulated by GDNF including the differentiation marker Neurog3. Our cultures of isolated seminiferous tubules, revealed a similar upregulation of Gra 1, Bcl6b and a downregulation of Neurog3. Interestingly, we observed a GDNF-dependent upregulation of Tex14, Sohlh1 and Kit and concomitant downregulation of Pou5f1 mRNAs. TEX14 is an essential component of germ cell intercellular bridges. In its absence, spermatogenesis is disrupted due to enhanced apoptosis of spermatocytes (Greenbaum et al. 2006). Inactivation of SOHLH1, a basic helix-loop-helix transcription factor that is expressed in germ cells, causes infertility by blocking differentiation of spermatogonia into spermatocytes (Ballow et al. 2006). Pou5f1 is a homeobox transcription factor required for the maintenance of totipotency of embryonic stem cells (Nichols et al. 1998, Niwa et al. 2000), is expressed in undifferentiated spermatogonia (Pesce et al. 1998) and is required for SSC maintenance in culture and for colonisation activity following testis germ cell transplantation (Dann et al. 2008). In the microarray analysis performed on mouse SSC lines Tex14, Sohlh1, Kit and Pou5f1 mRNA levels were unaffected by gdnf treatment (data accessible at NCBI GEO datasets, accession GDS2112 (Oatley et al. 2006). This discrepancy may well be related to the different culture conditions of the GDNF target cells in the two experimental models. However, since conditions of target cells in intact seminiferous tubules are more similar to the in vivo situation, it is likely that our data closely reflect the effect of GDNF in vivo. In future experiments, it will be interesting to perform a microarray analysis on cultures of intact seminiferous tubules to gain a more comprehensive list of GDNFregulated genes. We attempted to analyse whether upregulation of mRNA levels of our candidate genes results in increased protein levels. By western blot analysis of KIT and SOHLH1 we could not detect any significant difference between control and GDNFtreated seminiferous tubules. However, since GDNF target cells in the adult seminiferous tubules represent a very small population compared with all the other cell types, it is likely that an increase in protein level in target cells is hard to detect by Western blot analysis.

GDNF is critical for self-renewal maintenance of SSCs, both in vivo and in vitro. In the mouse, disruption of one GDNF allele leads to spermatogonial depletion and the appearance of Sertoli-cell-only tubules in the adult. In contrast, overexpression of GDNF causes an accumulation of clusters of undifferentiated spermatogonia (Meng et al. 2000). GDNF is also required for the initiation and maintenance of SSCs in 
culture (Kanatsu-Shinohara et al. 2003, Kubota et al. 2004). In this study, we show that GDNF also induces the transcription of genes involved in the differentiation of Aal into A1 spermatogonia. This differentiation becomes visible during stages VII and VIII, but the start of the process may be much earlier, for example in stages II-III when these cells stop proliferating and become quiescent. Our results show that the co-receptor for GDNF, GFRA1, is expressed in Aal spermatogonia in stages IX-XI and that the expression of this receptor decreases to below the immunohistochemical detection level thereafter. Maybe the high levels of GDNF during stages II-VI can compensate for the low levels of GFRA1 in Aal spermatogonia and still regulate transcription levels in these cells. Interestingly, in cultures of rat spermatogonia, GDNF was also shown to stimulate development of Aal (Hamra et al. 2007). How can GDNF impact both self-renewal and differentiation programmes in target cells? GDNF signal transduction in germ cells is elaborate and may lead to the activation of many signalling pathways, including the SRC family of tyrosine kinase, phosphatidylinositol-3-kinase/AKT (PI3K/AKT) and mitogen-activated protein kinase (MAPK) (BraydichStolle et al. 2007, Lee et al. 2007, Oatley et al. 2007, He et al. 2008). Work in other models has shown that GDNF acts through two different mechanisms, in cis or in trans, leading to the activation of different pathways. During activation in cis, the coreceptor RET interacts with the GFRA1-GDNF complex inside lipid rafts. However, in trans RET binds a soluble GFRA1-GDNF complex outside lipid rafts (Airaksinen \& Saarma 2002). In addition, GDNF may function in a RET-independent fashion (Sariola \& Saarma 2003). Therefore, GDNF may activate different transduction pathways in As vs chained cells eliciting divergent patterns of gene expression.

In conclusion, our data suggest that GDNF is not only involved in the regulation of the self-renewal of stem/progenitor cells, but also in further progression of chained undifferentiated spermatogonia.

\section{Materials and Methods}

\section{Animals}

C57BL/6 mice were used in all experiments. Animals were housed in a standard animal facility with free access to food and water, in accordance with the guidelines for animal care at the Sapienza University of Rome. All procedures were approved by the Department of Health Animal Care and Use Committee.

\section{Reagents and antibodies}

L-Glutamine, non-essential amino acids, HEPES, gentamicin, donkey serum and foetal bovine serum were acquired from Sigma-Aldrich. TO-PRO-3 fluorescent dye and TRIzol were acquired from Gibco, Invitrogen. Recombinant rat GDNF was acquired from R\&D Systems (Minneapolis, MN, USA). Transcriptor Reverse Transcriptase was acquired from Roche Applied Science (Milano, Italy). FluoCycle SybrGreen Kit was acquired from Euroclone (Milano, Italy). The antibodies used were goat anti-rat GFRA1 (Neuromics, Herford, Germany), mouse anti-human ZBTB16 (2A9; Calbiochem, Milano, Italy), Cy3-conjugated donkey anti-goat and FITC-conjugated donkey anti-mouse (Jackson Laboratories, Suffolk, UK). Vectashield mounting medium was acquired from Vector (Milano, Italy).

\section{Preparation of stage-specific seminiferous tubules}

Adult mice were killed, and the testes were removed and placed in a Petri dish containing PBS. The testes were decapsulated and transferred to a new Petri dish containing PBS. The seminiferous tubules were viewed on a transilluminating dissection microscope. Using forceps, the tubules were gently pulled apart, avoiding damaging them by squeezing or shaking. The stages of the seminiferous epithelial cycle were identified by the light absorption pattern (Parvinen \& Vanha-Perttula 1972) and the tubules were subdivided into three groups: stages II-VI (the strong spot), stages VII-VIII (the dark zone) and stages IX-XI (the pale zone) as described previously (Morena et al. 1995). Seminiferous tubules were either fixed for whole-mount immunofluorescence experiments or cultured for quantitative real-time PCR, ELISA and Western blot experiments as described later.

\section{Whole-mount immunofluorescence}

Whole-mount immunofluorescence on adult seminiferous tubules was performed as described previously (Corallini et al. 2006). Briefly, both mixed tubules and each group of stages were fixed in $4 \% \mathrm{v} / \mathrm{v}$ paraformaldehyde at $4{ }^{\circ} \mathrm{C}$ for $3 \mathrm{~h}$. Tubules were incubated overnight at $4{ }^{\circ} \mathrm{C}$ with mouse antiZBTB16 and goat anti-GFRA1 antibodies (1:100) followed by an incubation with species-specific secondary antibodies conjugated to FITC and Cy3 for $1 \mathrm{~h}$ at room temperature (RT). Nuclear staining was performed with TO-PRO-3 $(0.2 \mathrm{mg} / \mathrm{ml})$. Tubules were mounted with Vectashield medium and observed under a confocal microscope. Confocal photomicrographs of double-immunostained tubules were acquired with a Leica TCS SP2 (Leica, Milano, Italy) equipped with three laser lines (argon 488, 543 and $633 \mathrm{~nm}$ ). Each channel was acquired separately using specific laser lines to avoid bleed-through of the fluorochromes. Photomicrographs were made using LAS AF Software (Leica). Stacks of longitudinal Z sections, representing different layers of a tubule, were acquired.

\section{Quantification of type As, Apr and Aal spermatogonia in whole-mount immunofluorescence}

Stained tubules from three different experiments were observed using a confocal microscope with a $40 \times$ oil immersion objective. Cell counts were performed on stored microphotographs using LAS AF Software by placing a frame of $36100 \mu \mathrm{m}^{2}$ on the domed centre of the tubule. The total number of ZBTB16+ spermatogonia, including type As, Apr and Aal spermatogonia, their corresponding GFRA1 staining 
status and Sertoli cell nuclei were counted within the grid on randomly selected tubules. A ZBTB16+ cell was described as type As if surrounding cells within $25 \mu \mathrm{m}$ lacked ZBTB16 staining and exhibited a dissimilar nuclear morphology; furthermore, doublets of cells were designated type Apr when the internuclear distance was below $25 \mu \mathrm{m}$ (Tegelenbosch \& de Rooij 1993, Grisanti et al. 2009). In three different experiments, we analysed and counted 56 frames for stages II-VI corresponding to 737 ZBTB16+ cells, 44 for stages VII-VIII corresponding to 564 ZBTB16 + cells and 102 for stages IX-XI corresponding to 931 ZBTB16+ cells. The number of cells (single and chained) found in each group of stages were expressed per 1000 Sertoli cells because these cells do not proliferate in the adult testis and their number does not vary among stages.

\section{Semi-quantitative real-time PCR}

Thirty millimetres of each group of stages or total tubules were cultured in vitro for $16 \mathrm{~h}$ in 24-well culture plates with DMEM supplemented with antibiotics, L-glutamine, non-essential amino acids, HEPES and gentamicin. Afterwards, tubules were untreated or treated for $6 \mathrm{~h}$ with GDNF at $100 \mathrm{ng} / \mathrm{ml}$. To quantify relative expression levels of selected genes, total RNA from the tubules was purified using TRIzol reagent and quantified. Gene expression was evaluated by real-time PCR analysis. Total RNA/sample $(1 \mu \mathrm{g})$ was used for CDNA synthesis with Transcriptor Reverse Transcriptase. The resulting cDNA was used for real-time PCR, where analysis was performed in triplicate for each sample. CDNA was mixed with $0.2 \mu \mathrm{M}$ forward and reverse primers and $10 \mu \mathrm{l} 2 \times$ master mix to a final reaction volume of $20 \mu \mathrm{l}$. Reactions were performed on Opticon2 DNA Engine (MJ Research, Waltham, MA, USA). Primers used to detect target genes were designed and evaluated using the Primer3 Software (http://frodo.wi.mit.edu/ primer3) and ordered from Sigma-Genosys Oligo Synthesis (Supplementary Table 1, see section on supplementary data given at the end of this article). The amplification efficiency for each primer pair was determined by amplification of a linear standard curve of total cDNA (from 0.32 to 200 ng for Gfra1, Bcl6b, Neurog3, Tex14, Sohlh1 and Pou5f1; from 1.6 to $1000 \mathrm{ng}$ for Kit). All primer pairs showed good amplification linearity and efficiency (>95\%). Total cDNA levels were normalised against a $\beta$-actin control and presented either as the fold increase over the basal control or as arbitrary units. Expression levels of interest genes were also normalised against two other reference genes, Gapdh and Rn18s (18S), giving similar results (data not shown). Each real-time PCR assay was repeated at least two times in three different experiments and each sample was analysed in triplicate in each assay; mean values with S.E.M. were used for comparison.

\section{GDNF secretion}

Hundred millimetres of pieces of seminiferous tubules of each group of stages were seeded in 24-well culture plates with DMEM supplemented with antibiotics, L-glutamine, nonessential amino acids, HEPES $\mathrm{pH} 7.7$, gentamicin and $100 \mathrm{ng} / \mathrm{ml} \mathrm{FSH}$. GDNF production in the culture medium was measured at $24 \mathrm{~h}$, using the GDNF Emax ImmunoAssay System Kit (Promega, Milano, Italy) according to the manufacturer's instructions. The ELISA reaction was carried out in 96-well plates, and the optical densities were recorded by the Microplate reader at $450 \mathrm{~nm}$ wavelength. Results are from four independent experiments and are expressed as means \pm S.E.M.

\section{Statistical analysis}

Data were analysed to define the significance of the differences between the two groups using a $t$-test or, to compare many groups, using a one-way ANOVA followed by a post-hoc Bonferroni test or Dunn test.

\section{Supplementary data}

This is linked to the online version of the paper at http://dx.doi. org/10.1530/REP-11-0385.

\section{Declaration of interest}

The authors declare that there is no conflict of interest that could be perceived as prejudicing the impartiality of the research reported.

\section{Funding}

This study was supported by the Ministero Istruzione Università Ricerca (\#20083CBLPY_002), Agenzia Spaziale Italiana (\#l/065/08/0) and Sapienza University (\#C26V10RPR2).

\section{Acknowledgements}

We are grateful to Stefania Fera and Stefania De Grossi for their excellent technical assistance.

\section{References}

Airaksinen MS \& Saarma M 2002 The GDNF family: signalling, biological functions and therapeutic value. Nature Reviews. Neuroscience 3 383-394. (doi:10.1038/nrn812)

Ballow D, Meistrich ML, Matzuk M \& Rajkovic A 2006 Sohlh1 is essential for spermatogonial differentiation. Developmental Biology 294 161-167. (doi:10.1016/j.ydbio.2006.02.027)

Beumer TL, Roepers-Gajadien HL, Gademan IS, Lock TM, Kal HB \& de Rooij DG 2000 Apoptosis regulation in the testis: involvement of Bcl-2 family members. Molecular Reproduction and Development 56 353-359. (doi:10.1002/1098-2795(200007)56:3<353::AID-MRD4>3.0.CO;2-3)

Braydich-Stolle L, Kostereva N, Dym M \& Hofmann MC 2007 Role of Src family kinases and $\mathrm{N}-\mathrm{Myc}$ in spermatogonial stem cell proliferation. Developmental Biology 304 34-45. (doi:10.1016/j.ydbio.2006.12.013)

Buaas FW, Kirsh AL, Sharma M, McLean DJ, Morris JL, Griswold MD, de Rooij DG \& Braun RE 2004 Plzf is required in adult male germ cells for stem cell self-renewal. Nature Genetics 36 647-652. (doi:10.1038/ ng1366)

Corallini S, Fera S, Grisanti L, Falciatori I, Muciaccia B, Stefanini M \& Vicini E 2006 Expression of the adaptor protein $\mathrm{m}-\mathrm{Numb}$ in mouse male germ cells. Reproduction 132 887-897. (doi:10.1530/REP-06-0062)

Costoya JA, Hobbs RM, Barna M, Cattoretti G, Manova K, Sukhwani M, Orwig KE, Wolgemuth DJ \& Pandolfi PP 2004 Essential role of Plzf in maintenance of spermatogonial stem cells. Nature Genetics 36 653-659. (doi:10.1038/ng1367) 
Dann CT, Alvarado AL, Molyneux LA, Denard BS, Garbers DL \& Porteus MH 2008 Spermatogonial stem cell self-renewal requires OCT4, a factor downregulated during retinoic acid-induced differentiation. Stem Cells 26 2928-2937. (doi:10.1634/stemcells.2008-0134)

Greenbaum MP, Yan W, Wu MH, Lin YN, Agno JE, Sharma M, Braun RE, Rajkovic A \& Matzuk MM 2006 TEX14 is essential for intercellular bridges and fertility in male mice. PNAS 103 4982-4987. (doi:10.1073/ pnas.0505123103)

Grisanti L, Falciatori I, Grasso M, Dovere L, Fera S, Muciaccia B, Fuso A, Berno V, Boitani C, Stefanini M et al. 2009 Identification of spermatogonial stem cell subsets by morphological analysis and prospective isolation. Stem Cells 27 3043-3052. (doi:10.1002/stem.206)

Hamra FK, Chapman KM, Nguyen D \& Garbers DL 2007 Identification of neuregulin as a factor required for formation of aligned spermatogonia. Journal of Biological Chemistry 282 721-730. (doi:10.1074/jbc. M608398200)

He ZP, Jiang JJ, Kokkinaki M, Golestaneh N, Hofmann MC \& Dym M 2008 GDNF upregulates $\mathrm{C}$-fos transcription via the Ras/ERK1/2 pathway to promote mouse spermatogonial stem cell proliferation. Stem Cells $\mathbf{2 6}$ 266-278. (doi:10.1634/stemcells.2007-0436)

Hofmann MC, Braydich-Stolle L \& Dym M 2005 Isolation of male germ-line stem cells; influence of GDNF. Developmental Biology 279 114-124. (doi:10.1016/j.ydbio.2004.12.006)

Huckins C 1971 a Cell cycle properties of differentiating spermatogonia in adult Sprague-Dawley rats. Cell and Tissue Kinetics 4 139-154.

Huckins C $1971 b$ The spermatogonial stem cell population in adult rats. I. Their morphology, proliferation and maturation. Anatomical Record 169 533-557. (doi:10.1002/ar.1091690306)

Johnston DS, Olivas E, Dicandeloro P \& Wright WW 2011 Stage-specific changes in GDNF expression by rat Sertoli cells: a possible regulator of the replication and differentiation of stem spermatogonia. Biology of Reproduction 85 763-769. (doi:10.1095/biolreprod.110.087676)

Kanatsu-Shinohara M, Ogonuki N, Inoue K, Miki H, Ogura A, Toyokuni S \& Shinohara T 2003 Long-term proliferation in culture and germline transmission of mouse male germline stem cells. Biology of Reproduction 69 612-616. (doi:10.1095/biolreprod.103.017012)

Kubota H, Avarbock MR \& Brinster RL 2004 Culture conditions and single growth factors affect fate determination of mouse spermatogonial stem cells. Biology of Reproduction 71 722-731. (doi:10.1095/biolreprod.104.029207)

Lee J, Kanatsu-Shinohara M, Inoue K, Ogonuki N, Miki H, Toyokuni S, Kimura T, Nakano T, Ogura A \& Shinohara T 2007 Akt mediates selfrenewal division of mouse spermatogonial stem cells. Development 134 1853-1859. (doi:10.1242/dev.003004)

Lok D \& de Rooij DG 1983 Spermatogonial multiplication in the Chinese hamster. I. Cell cycle properties and synchronization of differentiating spermatogonia. Cell and Tissue Kinetics 16 7-18.

Lok D, Weenk D \& de Rooij DG 1982 Morphology, proliferation, and differentiation of undifferentiated spermatogonia in the Chinese hamster and the ram. Anatomical Record 203 83-99. (doi:10.1002/ar.1092030109)

Lok D, Jansen MT \& de Rooij DG 1983 Spermatogonial multiplication in the Chinese hamster. II. Cell cycle properties of undifferentiated spermatogonia. Cell and Tissue Kinetics 16 19-29.

Meng X, Lindahl M, Hyvonen ME, Parvinen M, de Rooij DG, Hess MW, Raatikainen-Ahokas A, Sainio K, Rauvala H, Lakso M et al. 2000 Regulation of cell fate decision of undifferentiated spermatogonia by GDNF. Science 287 1489-1493. (doi:10.1126/science.287.5457.1489)

Morena AR, Boitani C, de Grossi S, Stefanini M \& Conti M 1995 Stage and cell-specific expression of the adenosine $3^{\prime}, 5^{\prime}$ monophosphatephosphodiesterase genes in the rat seminiferous epithelium. Endocrinology 136 687-695. (doi:10.1210/en.136.2.687)

Nakagawa T, Sharma M, Nabeshima Y, Braun RE \& Yoshida S 2010 Functional hierarchy and reversibility within the murine spermatogenic stem cell compartment. Science 328 62-67. (doi:10.1126/science. 1182868)
Nichols J, Zevnik B, Anastassiadis K, Niwa H, Klewe-Nebenius D, Chambers I, Scholer H \& Smith A 1998 Formation of pluripotent stem cells in the mammalian embryo depends on the POU transcription factor Oct4. Cell 95 379-391. (doi:10.1016/S0092-8674(00)81769-9)

Niwa H, Miyazaki J \& Smith AG 2000 Quantitative expression of Oct-3/4 defines differentiation, dedifferentiation or self-renewal of ES cells. Nature Genetics 24 372-376. (doi:10.1038/74199)

Oakberg EF 1971 Spermatogonial stem-cell renewal in the mouse. Anatomical Record 169 515-531. (doi:10.1002/ar.1091690305)

Oatley JM, Avarbock MR, Telaranta AI, Fearon DT \& Brinster RL 2006 Identifying genes important for spermatogonial stem cell self-renewal and survival. PNAS 103 9524-9529. (doi:10.1073/pnas.0603332103)

Oatley JM, Avarbock MR \& Brinster RL 2007 Glial cell line-derived neurotrophic factor regulation of genes essential for self-renewal of mouse spermatogonial stem cells is dependent on src family kinase signaling. Journal of Biological Chemistry 282 25842-25851. (doi:10. 1074/jbc.M703474200)

Parvinen M \& Vanha-Perttula T 1972 Identification and enzyme quantitation of the stages of the seminiferous epithelial wave in the rat. Anatomical Record 174 435-449. (doi:10.1002/ar.1091740404)

Pesce M, Wang XY, Wolgemuth DJ \& Scholer H 1998 Differential expression of the Oct- 4 transcription factor during mouse germ cell differentiation. Mechanisms of Development 71 89-98. (doi:10.1016/ S0925-4773(98)00002-1)

Phillips BT, Gassei K \& Orwig KE 2010 Spermatogonial stem cell regulation and spermatogenesis. Philosophical Transactions of the Royal Society of London. Series B, Biological sciences 365 1663-1678. (doi:10.1098/ rstb.2010.0026)

de Rooij DG 2001 Proliferation and differentiation of spermatogonial stem cells. Reproduction 121 347-354. (doi:10.1530/rep.0.1210347)

de Rooij DG \& Janssen JM 1987 Regulation of density of spermatogonia in the seminiferous epithelium of the Chinese hamster: I. Undifferentiated spermatogonia. Anatomical Record 217 124-130. (doi:10.1002/ar. 1092170203)

de Rooij DG \& Lok D 1987 Regulation of density of spermatogonia in the seminiferous epithelium of the Chinese hamster: II. Differentiating spermatogonia. Anatomical Record 217 131-136. (doi:10.1002/ar. 1092170204)

Sariola H \& Saarma M 2003 Novel functions and signalling pathways for GDNF. Journal of Cell Science 116 3855-3862. (doi:10.1242/jcs.00786)

Schrans-Stassen BH, van de Kant HJ, de Rooij DG \& van Pelt AM 1999 Differential expression of c-kit in mouse undifferentiated and differentiating type A spermatogonia. Endocrinology 140 5894-5900. (doi:10.1210/ en.140.12.5894)

Suzuki H, Sada A, Yoshida S \& Saga Y 2009 The heterogeneity of spermatogonia is revealed by their topology and expression of marker proteins including the germ cell-specific proteins Nanos2 and Nanos3. Developmental Biology 336 222-231. (doi:10.1016/j.ydbio.2009.10.002)

Tadokoro Y, Yomogida K, Ohta H, Tohda A \& Nishimune Y 2002 Homeostatic regulation of germinal stem cell proliferation by the GDNF/FSH pathway. Mechanisms of Development 113 29-39. (doi:10.1016/S0925-4773(02)00004-7)

Tegelenbosch RA \& de Rooij DG 1993 A quantitative study of spermatogonial multiplication and stem cell renewal in the $\mathrm{C} 3 \mathrm{H} / 101$ F1 hybrid mouse. Mutation Research 290 193-200. (doi:10.1016/00275107(93)90159-D)

Zheng K, Wu X, Kaestner KH \& Wang PJ 2009 The pluripotency factor LIN28 marks undifferentiated spermatogonia in mouse. BMC Developmental Biology 9 38. (doi:10.1186/1471-213X-9-38)

Received 12 October 2011

First decision 31 October 2011

Accepted 5 December 2011 